\title{
Generating Apparatus for Gas Heat Pump System using Sensorless-Controlled Permanent Magnet Synchronous Generator
}

\author{
Akio Toba Member (Fuji Electric Advanced Technology Co., Ltd.) \\ Kouetsu Fujita Member (Fuji Electric FA Components and Systems Co., Ltd.) \\ Toshihiro Maeda Non-member (Fuji Electric FA Components and Systems Co., Ltd.) \\ Tomohiko Kato Non-member (Aisin Seiki Co., Ltd.)
}

Keywords: gas heat pump, permanent magnet generator, sensorless control, free-run startup

\section{Introduction}

Gas heat pump system (GHP) is an efficient air-conditioning system, introduced about 40,000 sets per year in Japan. In the system, compressors are driven by a gas engine, both of which are mounted in an outside unit. In the outside unit, there are electric components as fans and pumps. Therefore, the conventional outside unit needs dual energy sources; the gas line and the electric power grid.

We propose a new configuration of the outside unit, in which a generator is equipped, driven by the gas engine, and feeds the electric components inside. The electric power grid works only as a backup, then the capacity of the electricity receiving apparatus can be reduced.

The major topic of the system are as follows:

1) The utilization of a permanent magnet generator(PMG) controlled by a PWM rectifier, for high efficiency and power factor.

2) Sensorless control of the PMG for the durability to the heat and vibration caused by the gas engine.

3) Starting technique of the system while the engine is rotating; Free-run startup technique.

\section{System}

2.1 Overview System configuration is as shown in Fig. 1 . The controller has a regulator for the DC bus voltage to keep the voltage to the reference value, which is higher than the power grid

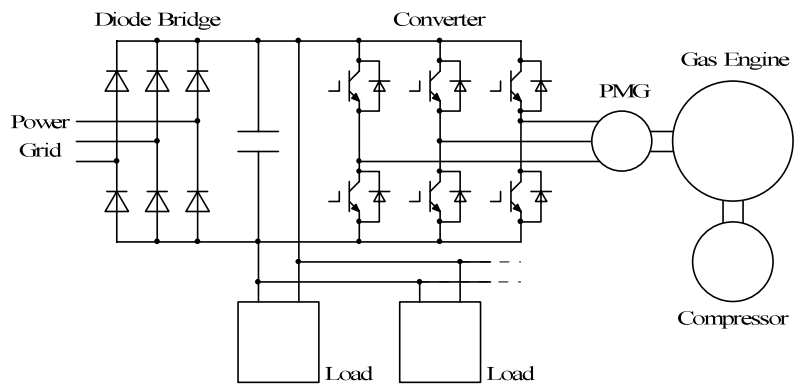

Fig. 1. System configuration

Table 1. Major specifications

\begin{tabular}{|c|c|}
\hline Rated power & $1.45 \mathrm{~kW}$ \\
\hline Speed range & $1385-3600 \mathrm{r} / \mathrm{min}$. \\
\hline Max. ambient temp. & 70 degree C \\
\hline Rated efficiencies & Conv: $95 \%$, PMG $92 \%$ \\
\hline Power grid voltage & $200 \mathrm{~V}$ \\
\hline
\end{tabular}

voltage. Then all the power required from the loads are fed by the PMG. When the generated power is limited by the controller to a lower value than the load power, the DC bus voltage $\left(\mathrm{E}_{d c}\right)$ falls down and the power shortage is compensated from the power gred via the diode bridge. Major specifications of the system are in Table 1.

2.2 Technologies The basic theory of the sensorless control is based on so colled 'the extended-emf' concept. The error angle between the reference frames of the rotor (d-q) and the controller (dc-qc) is estimated continuously and kept to be zero, by which the controller can regulate the $\mathrm{d}$ - and q- axis currents independently.

A new technique of the free-run startup is proposed, in which the switches of the rectifier is turned on and off in turn, depending on the resultant current flow. The advantage of the method is that the control of the switches is just sequencial and complecated calculation is not required.

\section{Experimental Results}

Fig. 2 shows the system operation with sudden speed changes between the bottom and top speeds at rated DC load. The system is confirmed to be stable with the speed changes and the step change of the load. When the speed is low, the PMG can not produce enough power because of the current limiter, then $\mathrm{E}_{d c}$ is low and the $\mathrm{i}_{a c}$ (power grid current) is flown in. When the speed is high, the generated power is enough to feed the load and $\mathrm{E}_{d c}$ is regulated to the reference value $(300 \mathrm{~V})$.

\section{Summary}

The system is tested thoroughly and confirmed to be highly stable and robust, which details are described in the full paper.

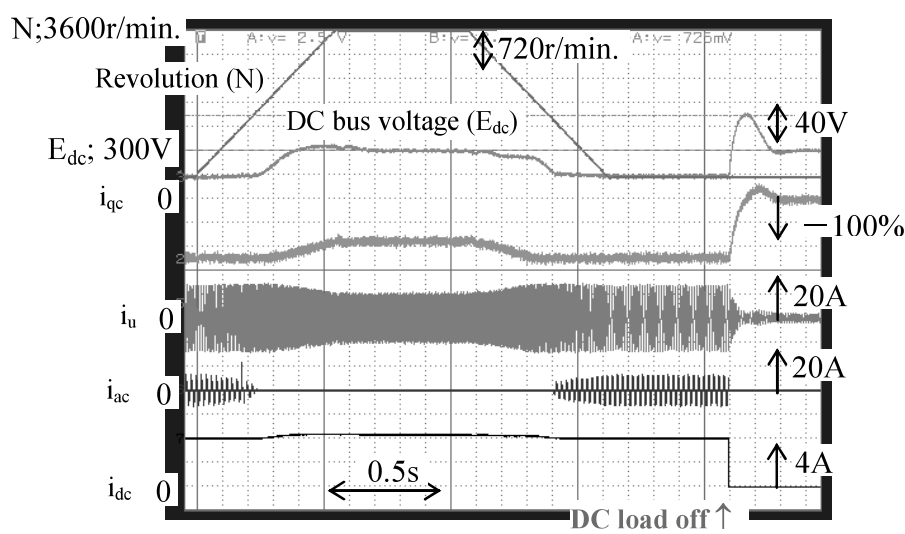

Fig. 2. System response to sudden speed changes 


\title{
Generating Apparatus for Gas Heat Pump System using Sensorless-Controlled Permanent Magnet Synchronous Generator
}

\author{
Akio Toba* \\ Kouetsu Fujita** Member \\ Toshihiro Maeda** Non-member \\ Tomohiko Kato*** Non-member
}

\begin{abstract}
A unique generating system for Gas heat pump system (GHP) is presented. The GHP is an air-conditioning system, in which the compressors are driven by a gas engine. The proposed system is applied to the outside unit of GHP to feed the electrical equipments inside. The system utilizes a permanent magnet synchronous generator, which is connected to the gas engine, to realize high-efficiency and small-size. The generator is controlled by a converter with sensorless control technology to eliminate the position sensor. Another major topic is the "free-run startup" technique to start the converter when the generator is rotating. The system configuration and principles of the techniques are set forth, followed by experimental results which show that the system works properly and successfully.
\end{abstract}

Keywords: gas heat pump, permanent magnet generator, sensorless control, free-run startup

\section{Introduction}

Gas heat pump system (GHP) is an efficient air-conditioning system, in which a compressor is driven by a gas engine, and is broadening its application to the facilities as supermarkets, schools, office buildings, etc. Fig. 1 shows an outlook of the outside unit of a GHP, which capacity is $20 \mathrm{HP}$ $(15 \mathrm{~kW})$.

In the outside unit, there are fans for cooling, pumps to circulate coolant for the engine, and some other components, which require electricity. Conventional GHPs obtain the electricity from the power grid, i.e. dual energy sources are needed.

To overcome this redundancy, we developed an outside unit of the GHP equipped with a generator to feed the electrical components inside. Since the generator is coupled with the gas engine, the energy source can be unified to the gas line. The major topics of the developed generating system are as follows:

1) To realize high-efficiency and small-size, a convertercontrolled permanent magnet generator (PMG) is used.

2) Because of high operating temperature and mechanical vibration, the position sensor of the rotor must be eliminated. Then a sensorless control is applied.

3) The converter is run and stopped arbitrarily while the generator is rotating. Then a "free-run startup" technique of the converter is adopted.

\footnotetext{
* Electronics Technology Laboratory, Fuji Electric Advanced Technology Co., Ltd.

1, Fuji-machi, Hino, Tokyo 191-8502

** Inverter Value Engineering Center, Fuji Electric FA Components and Systems Co., Ltd.

5520, Minami-Tamagaki-cho, Suzuka, Mie 513-8633

*** Energy Engineering Department, Aisin Seiki Co., Ltd.

2-1, Asahi-machi, Kariya, Aichi 448-8650
}

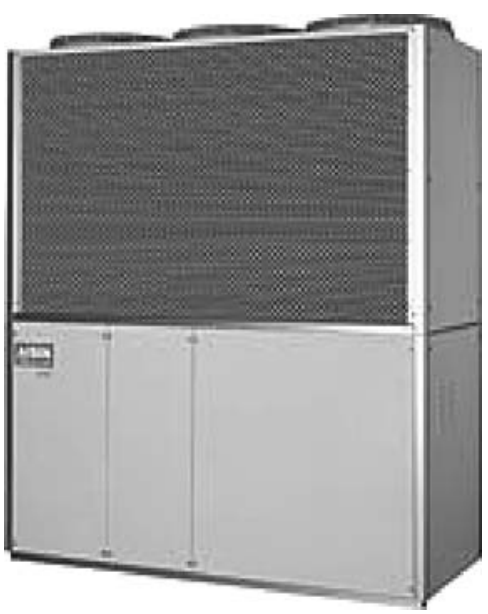

Fig. 1. Outside unit of Gas heat pump system (20 HP)

\section{System Configuration and Specifications}

Fig. 2 shows the system configuration. A gas engine drives both the compressor for the air-conditioning and the PMG. The PMG is a three-phase type, which is connected to a converter. The loads; the fans and the pumps, are all fed by inverters, and then the DC inputs of those loads are connected to the DC output of the converter. A diode bridge is also equipped to the DC part, of which the AC input is connected to the power grid. This works as a backup, which operates only in two occasions: start-up of the whole system until the engine operation becomes stable, and when the compressor requires most or the all of the power of the engine and then a limiter for the generation is applied. Although the dual power sources still exist, the capacity of the electricity receiving apparatus can be small, since multiple GHPs are used at the same site usually and they can take the electricity from the 


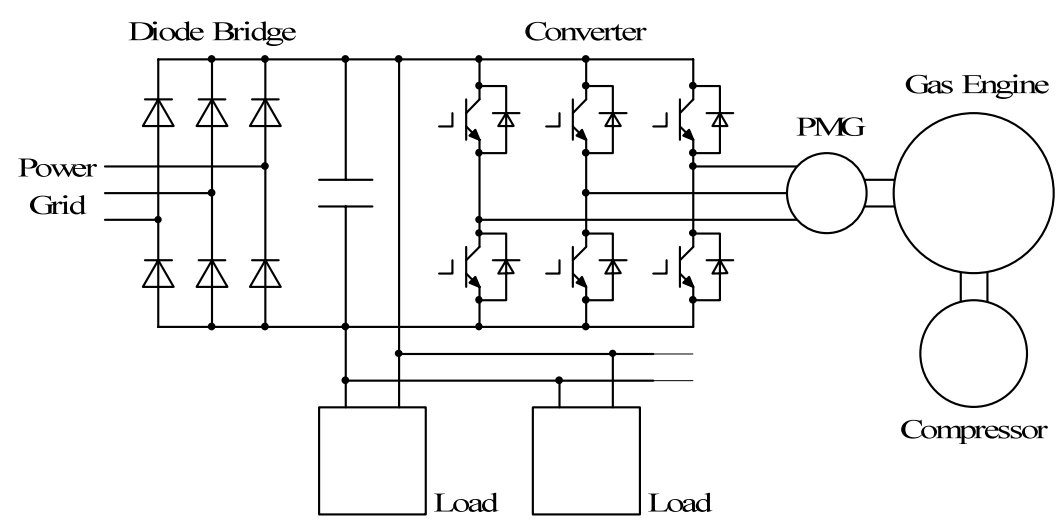

Fig. 2. Generating system configuration

Table 1. Specifications of generating system

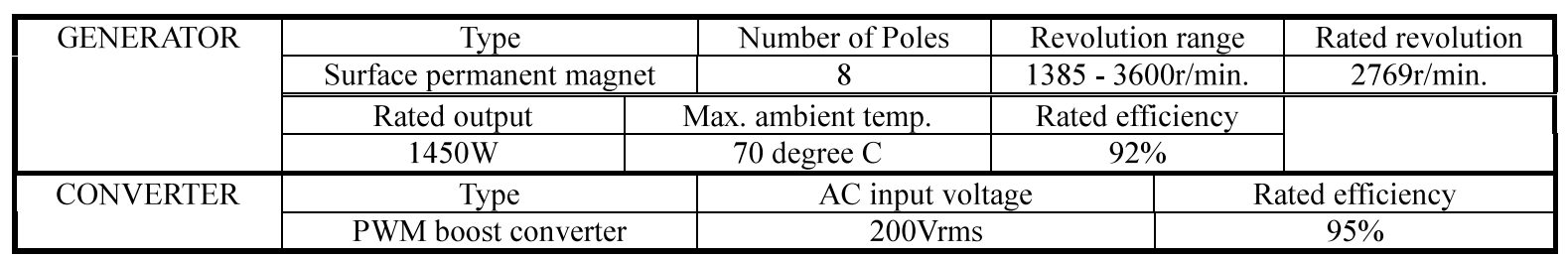

power grid alternately.

Table 1 describes the specifications of the developed system. The PMG is a surface permanent magnet (SPM) type. The reason is that the SPM type can realize larger torque per volume ratio than the interior permanent magnet type with the specifications in this time, and thus the generator can be lighter and smaller.

\section{Technologies}

3.1 Power Flow Control with Sensorless Drive The control block diagram and the relationship of control reference frames are shown in Fig. 3.

The controller has its own rotational reference frame; dcqc, for the basis of the 2-axis voltage and current control. The dc-qc reference frame tracks the d-q reference frame of the rotor, where d-axis is directing the $\mathrm{N}$-pole and q-axis is orthogonal to the d-axis. To realize the tracking, the error angle between dc-qc and d-q reference frames; $\delta$ is always estimated and kept to be zero ${ }^{(1)}$. This is carried out by the $\delta$ estimator and the PI regulator in the coordinate tracking part. The estimation method of the error angle $\delta$, which is proposed in Ref. (2) and tested in Ref. (1), is adopted. A brief explanation of the estimation theory can be described as follows.

The voltages in d- and q-axes, $v_{d}$ and $v_{q}$, are expressed as the following equation in general.

$$
\left[\begin{array}{l}
v_{d} \\
v_{q}
\end{array}\right]=\left[\begin{array}{cc}
R+p L_{d} & -\omega L_{q} \\
\omega L_{d} & R+p L_{q}
\end{array}\right]\left[\begin{array}{l}
i_{d} \\
i_{q}
\end{array}\right]+\left[\begin{array}{c}
0 \\
\omega \psi
\end{array}\right]
$$

where $R$ is the phase resistance, $L_{d}$ and $L_{q}$ are the inductances in $\mathrm{d}$ - and q-axes, $\omega$ is the electrical angular velocity, $i_{d c}$ and $i_{q c}$ are the currents in dc- and qc-axes, and $\psi$ is the coil flux linkage due to the permanent. From the coordinate definition as shown in Fig. 3, a general equation for $v_{d c}$ and $v_{q c}$ is given as

$$
\left[\begin{array}{l}
v_{d c} \\
v_{q c}
\end{array}\right]=\left[\begin{array}{cc}
\cos \delta & \sin \delta \\
-\sin \delta & \cos \delta
\end{array}\right]\left[\begin{array}{l}
v_{d} \\
v_{q}
\end{array}\right]
$$

Here, pseudo-voltages $\hat{v}_{d c}$ and $\hat{v}_{d c}$ are calculated as

$$
\left[\begin{array}{l}
\hat{v}_{d c} \\
\hat{v}_{q c}
\end{array}\right]=\left[\begin{array}{cc}
R+p L_{d} & -\omega L_{q} \\
\omega L_{q} & R+p L_{d}
\end{array}\right]\left[\begin{array}{c}
i_{d c} \\
i_{q c}
\end{array}\right] \ldots
$$

Note that $L_{d}$ and $L_{q}$ in the second row are exchanged from the usual expression as (1), although the values are the same in the case of a non-salient machine. Then, with a simple calculation below, the sine and cosine values of the phase error $\delta$ can be obtained separately.

$$
\begin{aligned}
{\left[\begin{array}{l}
v_{d e} \\
v_{q e}
\end{array}\right] } & =\left[\begin{array}{l}
v_{d c} \\
v_{q c}
\end{array}\right]-\left[\begin{array}{l}
\hat{v}_{d c} \\
\hat{v}_{q c}
\end{array}\right] \\
& =\left\{\omega\left(L_{d}-L_{q}\right) i_{d}-p\left(L_{d}-L_{q}\right) i_{q}+\omega \psi\right\}\left[\begin{array}{c}
\sin \delta \\
\cos \delta
\end{array}\right]
\end{aligned}
$$

Finally the error angle $\delta$ is introduce as

$$
\delta=\tan ^{-1}\left(v_{d e} / v_{q e}\right)
$$

This calculation method is the very basis of the "extended emf' concept in the later-year literatures as Ref. (4) and Ref. (5). The main reasons for the adoption of this method are - accuracy and explicitness of the calculation due to the closed-form introduction as described above, and

- high-reliability based on our former research experiences $^{(1)}$, which is the most important for a product application.

Since the rotational speed of the generator is determined by the engine, there is no speed regulator in the system. Instead, there is a DC voltage regulator to adjust the qc-axis current. The generated electricity is proportional to the qaxis current, which equals the qc-axis current if the two axes are identical, when the rotational speed is constant. Therefore, by determining the qc-axis current as the output of the DC voltage regulator which works to keep the DC bus voltage constant, the generator produces as much electricity as required by the load. During the operation, no power flows 

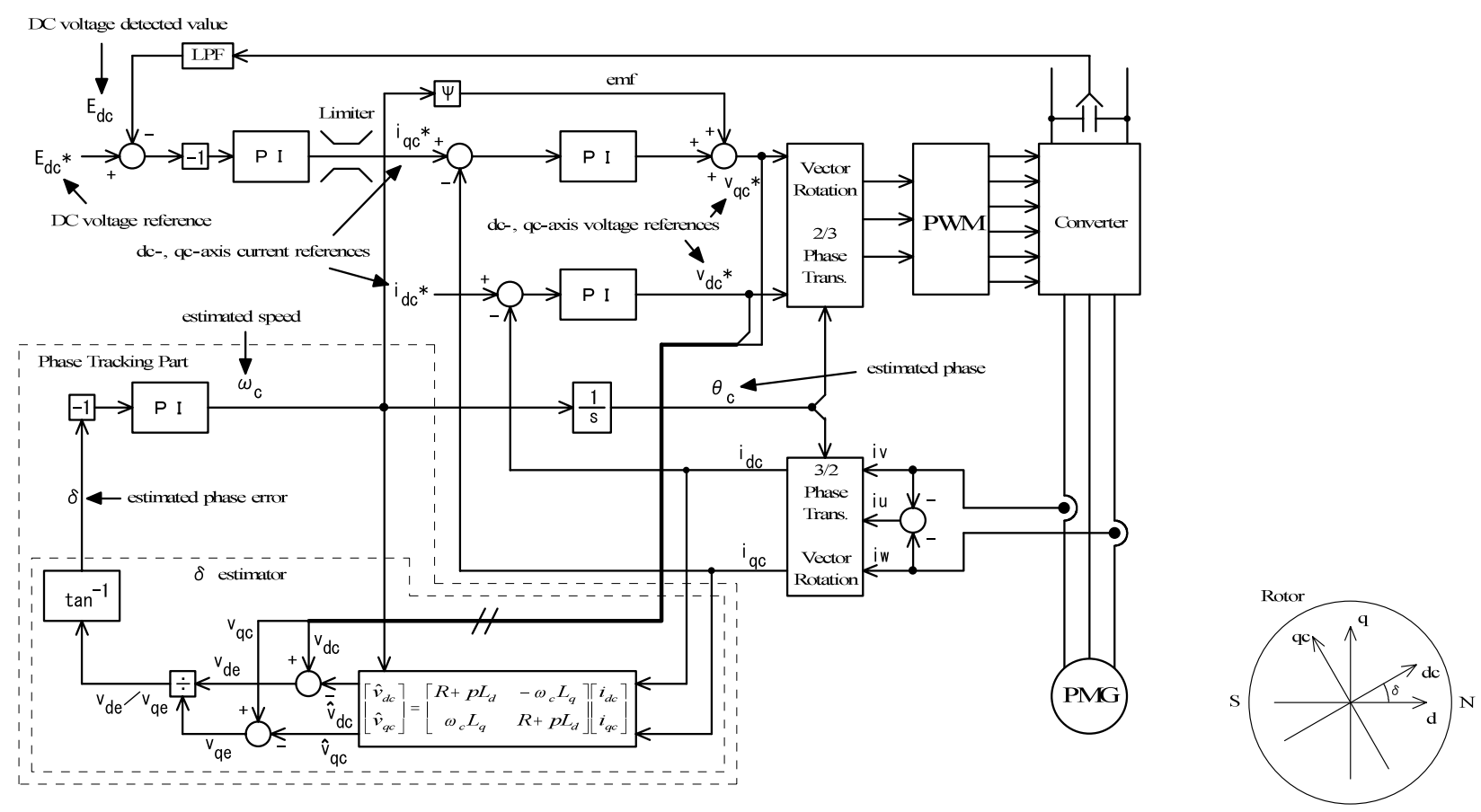

Fig. 3. Control block diagram and reference frames

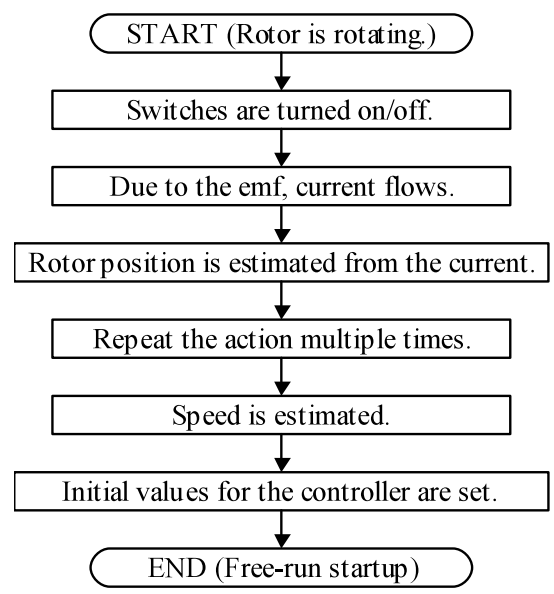

Fig. 4. Flowchart of free-run startup

through the diode bridge as long as keeping the DC bus voltage higher than the peak voltage of the power grid. And when the qc-axis current is limited by a limiter on the output of the DC voltage regulator, or when the converter is not in operation, the generated electricity becomes smaller than the load electricity, which results in the fall of the DC voltage, and then the power shortage is compensated from the power grid.

3.2 Free-run Startup In the system, the generation system is always started when the engine is rotating. Since there are no sensors for the rotor position or for the generator terminal voltages, the controller of the converter has no information about the position or the speed of the rotor at the starting. Then, a "free-run startup" technique is needed.

The flowchart of the startup sequence is shown in Fig. 4. The principle of the method is to obtain the rotor information from the current when some switches are turned on during the rotation, which depends on the emf. The point is the organization of the ways to operate the switches and to extract
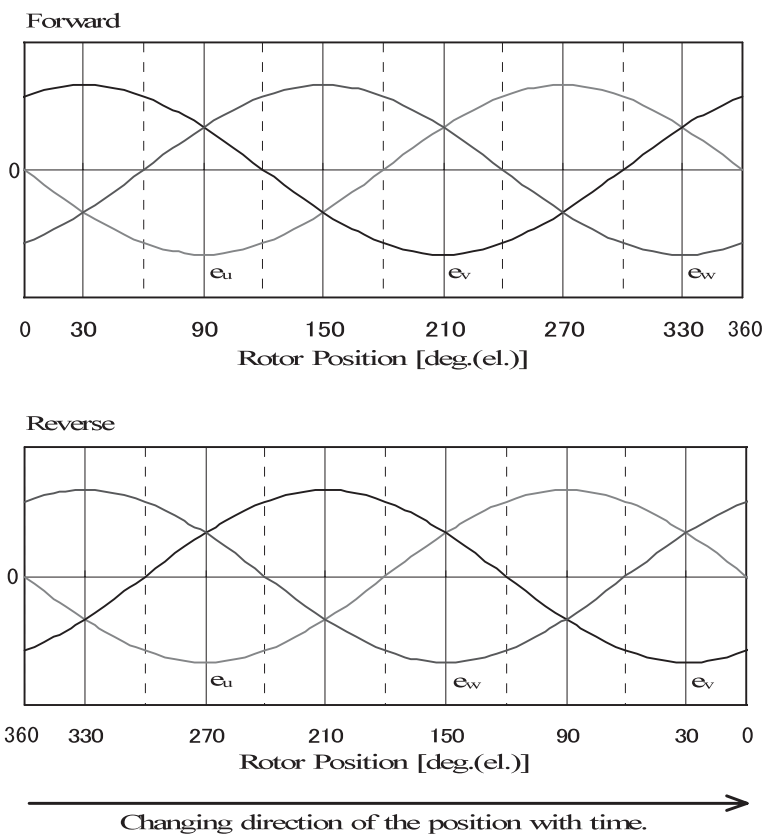

Fig. 5. emf waveforms vs. rotor position

the desired information from the current.

In Ref. (3), one method of the free-run startup has been proposed and experimentally verified, in which all the motor terminals are short-circuited instantaneously by the inverter switches. Although the method is successful, the calculation to extract the rotor information from the current is relatively complex.

Then a new method is proposed here: Fig. 5 shows the relationship between the rotor position in electrical degree and the waveforms of the emf with the forward and the reverse directions. In the proposed method, only one switch is turned on in one instance. 


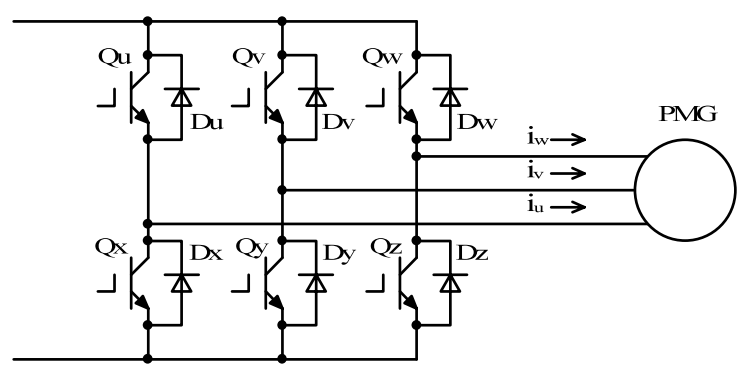

(a) Converter and PMG

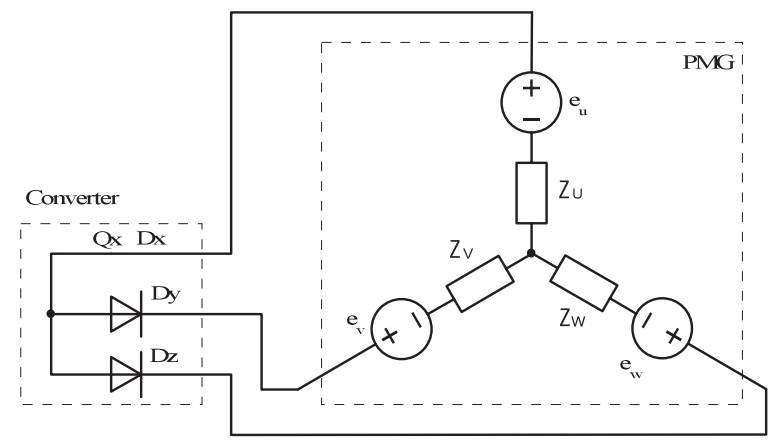

(b) Equivalent circuit when Qx is turned on

Fig. 6. Switching operation and resultant circuit for free-run startup

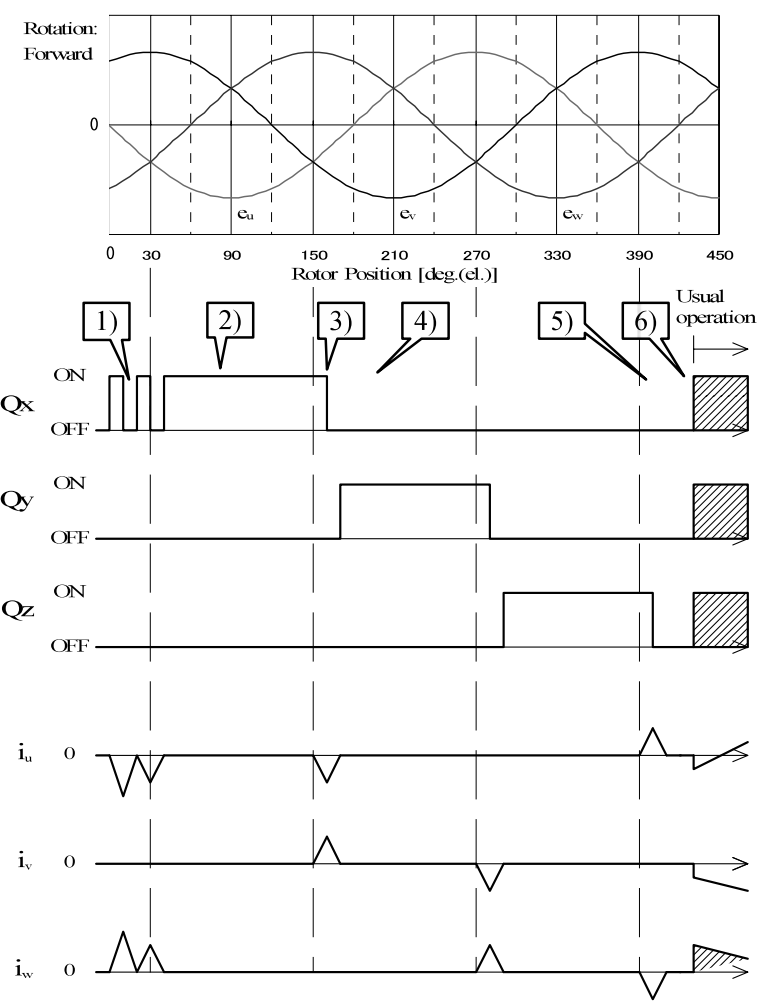

1) Repetitive ON-OFF until current does not flow with ON.

2) Qx is kept ON until current starts to flow.

3) With the current flow, the rotor position and direction are detected.

4) Knowing the direction, Qy is turned-on until current starts to flow.

5) Speed is calculated from the time interval between 3) and 5).

6) Speed, position, and direction are preset to the controller and the system is started.

Fig. 7. Diagram to show principle of free-run startup operation

The operation principle can be explained as follows. Suppose the switch Qx of the converter in Fig. 6(a) is turned on. The equivalent circuit of the system at that case is as shown in Fig. 6(b), in which the PMG is expressed as the combination of the emf; e and the impedance; $Z$ of each phase. It can be realized from the observation of Fig. 5 and Fig. 6 that current does not flow if the rotor position is between 30 to 150 degrees with the forward rotation, due to the reverse blocking of the diodes Dy and Dz. Then if the switch Qx is kept turned on, current starts to flow through phases $\mathrm{U}$ and $\mathrm{V}$ right after the rotor passes 150 degrees. Likewise, if the rotation is reverse, current starts to flow through phase $\mathrm{U}$ and $\mathrm{W}$ when the rotor passes 210 degrees. This phenomenon is highly usable to acquire the pinpoint rotor position and the rotational direction. After judging the current flow, the switch Qx can be turned off and the current decreases to zero. Moreover, it is obvious that the rotational speed can be calculated by two rotor positions obtained at specific instances. When the rotor position, speed, and the rotational direction are known, the system can be started with presetting the control variables based on those rotor information. Fig. 7 is the summary of the operation principle described above with the case of forward revolution.

The advantages of the proposed method to the one in Ref. (3) are that the calculation and the judgment are much simpler and that the influence of the detection error of the current sensors is smaller. Those merits are because the rotor position and the rotational direction are introduced only by observing if current is flowing or not, which on the other hand are obtained from the calculations using the values of three phase currents in the method of Ref. (3).

\section{Experimental Results}

Experiments have been carried out to evaluate the system performances. Fig. 8 shows the configuration of the experimental setup. To evaluate the generating system in detail, a coupled motor-and-generator setup, with a torque sensor inbetween, has been used instead of the real system where the generator is directly coupled to the engine.

4.1 Free-run Startup and Sensorless Drive Fig. 9 shows the generator currents and the DC bus voltage waveforms at the starting. It can be seen that the free-run startup is working adequately in the lowest and the highest speeds. The zoomed waveforms at the starting show the detailed operation of the free-run startup sequence. At the very beginning of the switches operating period, relatively large, pulse-like currents are flowing. This is due to the switch Qx in Fig. 6(a) is turned on when the rotor position is outside of 30 to 150 degrees range during the forward rotation. At that case, current starts to flow immediately after the switch is turned on. The sequence is set so that the switch is turned off at that case. Then pulse-like currents flow several times, which are to reduce the calculation error in the rotational speed.

After the startup, the sensorless drive begins and keeps the current stable. The DC voltage is increased by the generating operation.

4.2 Response to Rotor Position Disturbance Fig. 10 shows the system response to step changes of the estimated phase $\theta \mathrm{c}$ in Fig. 3. The amount of the step change is $30 \mathrm{de}-$ grees. Although this kind of large disturbance never occurs in the actual use, it is valuable to evaluate the system performance with such an eccentric case to guarantee the stability. From Fig. 8 , it can be confirmed that the system stays highly 


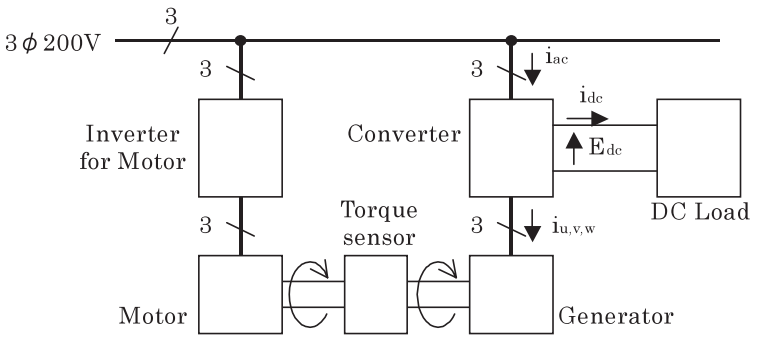

Fig. 8. Experimental setup

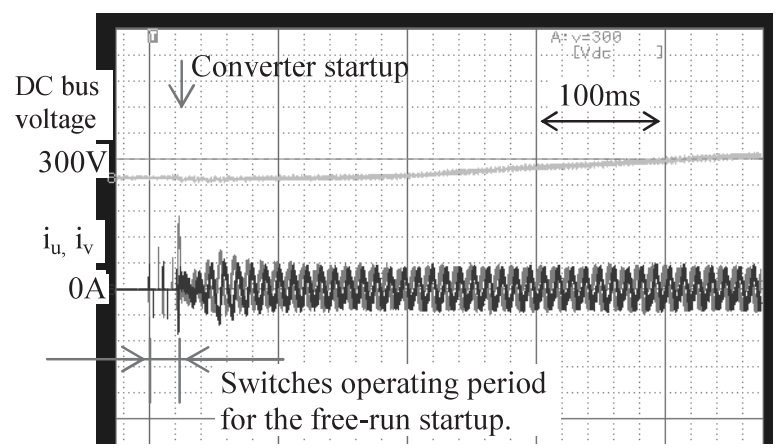

(a) Speed; $1385 \mathrm{r} / \mathrm{min}$

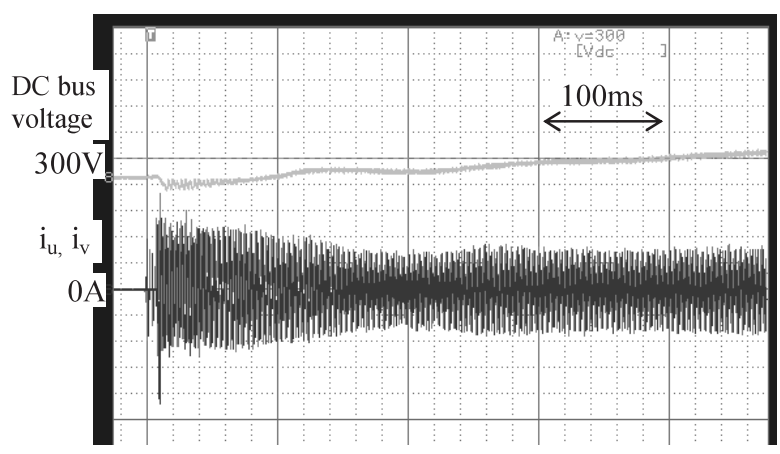

(b) Speed; $3600 \mathrm{r} / \mathrm{min}$

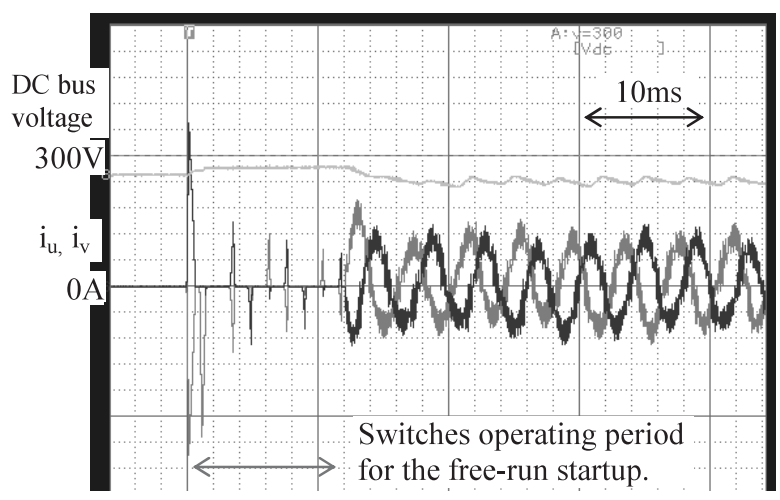

(c) Startup operation (Speed; $3600 \mathrm{r} / \mathrm{min}$. , zoomed) DC bus voltage; $20 \mathrm{~V} / \mathrm{div} ., \mathrm{i}_{u}, \mathrm{i}_{\mathrm{v}} ; 2 \mathrm{~A} / \mathrm{div}$.

Fig. 9. Free-run startup and sensorless drive

stable with the positive and negative disturbances, and that the estimated phase error $\delta$ is accurately calculated.

The same tests have been carried out with different speeds, and also with changing the parameters in the $\delta$ estimator, i.e. the nominal values of resistance and inductance, to evaluate the parameters sensitivity. In the all tests the stability of the system has been confirmed. With those results, the robustness of the system is verified and the adjustments and performance evaluations of the major-loop; the DC voltage

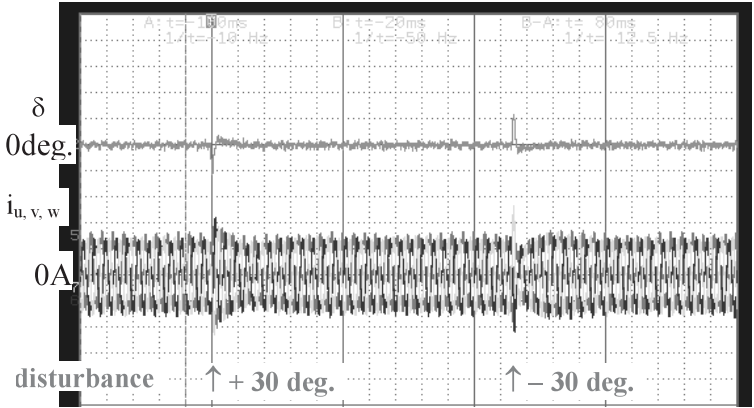

(a) speed: $1800 \mathrm{r} / \mathrm{min}$
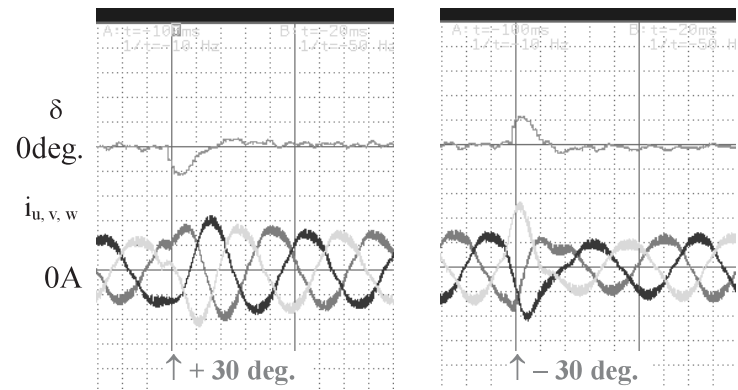

(b) speed: $1800 \mathrm{r} / \mathrm{min}$ (zoomed)

estimated phase error $\delta ; 24 \mathrm{deg} /$ div., current; $5 \mathrm{~A} /$ div.

Fig. 10. System response to step changes of rotor position

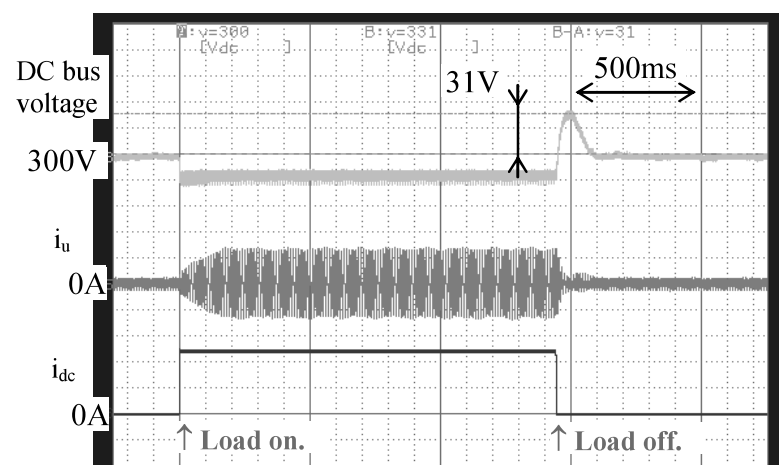

(a) Speed; $1385 \mathrm{r} / \mathrm{min}$

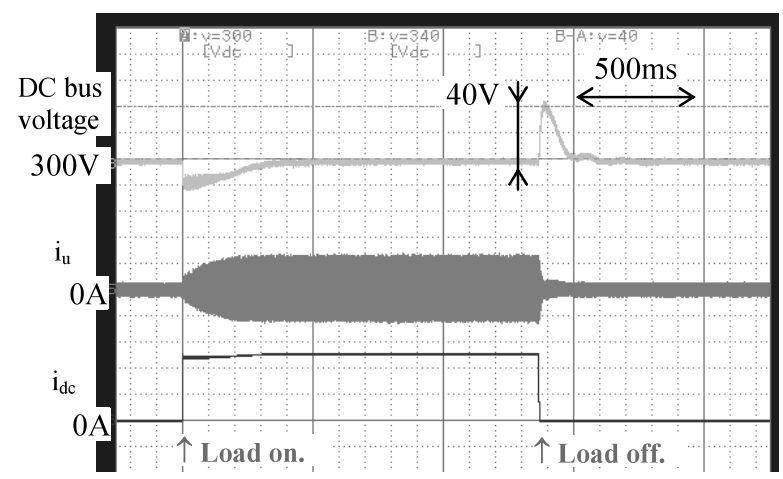

(b) speed; $3600 \mathrm{r} / \mathrm{min}$

DC bus voltage; $20 \mathrm{~V} /$ div., iu; $10 \mathrm{~A} /$ div., idc; $2 \mathrm{~A} /$ div.

Fig. 11. System response to sudden load changes

regulator, can be carried out.

4.3 Response to Load Change Fig. 11 depicts the system response to step changes of the DC load. As to be seen, the system is stable and the peak of the DC voltage at the load-off instant is $340 \mathrm{~V}$, which is low enough to the over voltage level $(400 \mathrm{~V})$. When the rotor speed is low, the 


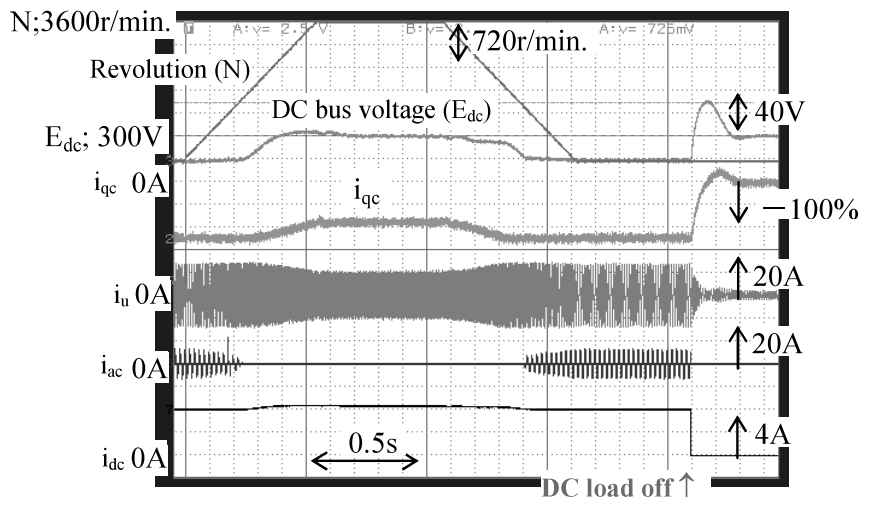

Fig. 12. System response to sudden speed changes

Table 2. Efficiency at the rated operation

\begin{tabular}{|l|c|}
\hline Generator & $92.6 \%$ \\
\hline Converter & $95.6 \%$ \\
\hline Total & $88.6 \%$ \\
\hline
\end{tabular}

generator can not yield as much electricity as the load requires, since the generated electricity per current ratio decreases with the rotor speed in general, and the generator current is limited to a certain value. Therefore, at the low speed operation the DC voltage falls when the DC load is applied and then the residual power is fed from the power grid (Fig. 11(a)). However, when the rotor speed is high, the generator can produce the whole amount of the electricity that the DC load requires, and the DC voltage is kept to the reference value (300 V) (Fig. 11(b)).

4.4 Response to Speed Change The system response to quick changes of the rotor speed is shown in Fig. 12. The rate of the speed change is $4000 \mathrm{r} / \mathrm{min} . / \mathrm{s}$, which is 10 times larger than the prescribed value. In spite of this rapid change, the sensorless drive is not disturbed and kept stable. It can be seen that the amplitude of the qc-axis current $\mathrm{i}_{\mathrm{qc}}$ becomes smaller when the speed is high, and is limited to a certain value when the speed is low, which is due to the same reason as explained in 4.3 .

4.5 Efficiency The system efficiency at the rated operation is summarized in Table 2. Both the generator and the converter satisfy the specifications.

\section{Conclusions}

A unique generating system for the Gas heat pump system with the sensorless-controlled permanent magnet generator is presented. Major electrical evaluations are completed and the results are satisfactory. Based on these prototype evaluations, production types are currently under developed.

The researches of the sensorless vector control for the permanent magnet machines have been widely carried out in the past, while its applications have not yet been gaining popularity. The generating system as described in this paper could be one of the hopeful applications of it, which requires the elimination of the position sensor due to the limitations from temperature and vibration, high efficiency, and current regulation.

(Manuscript received April 22, 2005,

revised Oct. 17, 2005)

\section{References}

( 1 ) T. Aihara, A. Toba, T. Yanase, A. Mashimo, and K. Endo: "Sensorless Torque Control of Salient-Pole Synchronous Motor at Zero-Speed Operation", IEEE Trans. on Power Electron., Vol.14, No.1, pp.202-208 (1999)

( 2 ) H. Watanabe, T. Isii, and T. Fujii: "DC-Brushless Servo System without Rotor Position and Speed Sensor”, Proc. IECON'87, Vol.1, pp.228-234 (1987)

( 3 ) A. Toba, T. Aihara, and T. Yanase: "A Starting Method of PM Motor Drive System without Position-, Speed- nor Voltage-Sensors in the Rotating Condition", Proc. of IEE-J Annual Meeting, No.135, pp.111-112 (1997) (in Japanese)

( 4 ) S. Morimoto, K. Kawamoto, M. Sanada, and Y. Takeda: "Sensorless control strategy for salient-pole PMSM based on extended EMF in rotating reference frame", IEEE Trans. IA, Vol.38, No.4, pp.1054-1061 (2002-4)

( 5 ) Z. Chen, M. Tomita, S. Ichikawa, S. Doki, and S. Okuma: "Sensorless Control of Interior Permanent Magnet Synchronous Motor by Estimation of an Extended Electromotive Force”, Proc. of IEEE IAS Annual Meeting (2000)

Akio Toba (Member) He received the B.E. and M.E. degrees in elec-

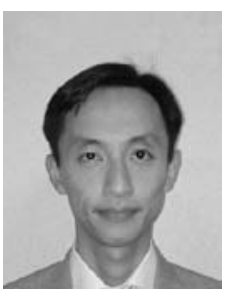
trical engineering both from Tokyo Metropolitan University, Tokyo, Japan, in 1992 and 1994, respectively. Since 1994, he has been with Fuji Electric R\&D Co., Ltd. (currently Fuji Electric Advanced Technology Co., Ltd.), Tokyo, Japan. From 1997 to 1999, he was a Visiting Scholar in the Department of Electrical and Computer Engineering, University of WisconsinMadison, U.S.A. He received the 1st 'Isao Takahashi' Award from the Industry Application Society of IEEJ, in 2004. His R\&D interests include power electronics applications, motor drive systems, and permanent magnet machines. He is a member of the IEEE, and the Robotics Society of Japan.

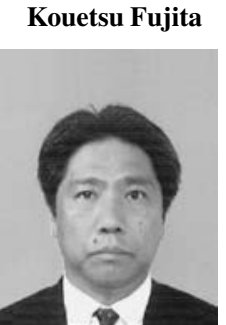

(Member) He received B.E. and M.E. degrees in electrical and electronics engineering both from Nagaoka University of Technology, Niigata, Japan, in 1981 and 1983, respectively. From 1983 to 1999, he was with Fuji Electric R\&D Co., Ltd. and moved to Fuji Electric FA Components and Systems, where he is currently General Manager of the Inverter Design Section in Mie, Japan. His R\&D interests include power electronics applications and motor drive systems. He received the Prize Paper Award from IEEJ in 1984.

Toshihiro Maeda (Non-member) He received the B.E. and M.E. degrees in electrical and electronics engineering both from Toyohashi University of Technology, Aichi, Japan, in 1996 and 1998, respectively. Since 1998, he has been with Fuji Electric FA Components and Systems in Mie, Japan. He is dealing with development and design of motor drive systems.

Tomohiko Kato

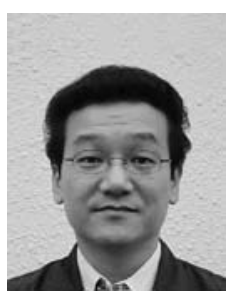

Non-member) $\mathrm{He}$ is currently with Aisin Seiki Co. and dealing with development of Gas Heat Pump airconditioning systems. 